\title{
Home-based motor imagery intervention improves functional performance following total knee arthroplasty in the short term: a randomized controlled trial
}

\author{
Armin H. Paravlic ${ }^{1}$, Nicola Maffulli ${ }^{2,3,4^{*}} \mathbb{D}$, Simon Kovač ${ }^{5}$ and Rado Pisot ${ }^{1,6}$
}

\begin{abstract}
Background: Motor imagery (MI) is effective in improving motor performance in the healthy asymptomatic adult population. However, its possible effects among older orthopaedic patients are still poorly investigated. Therefore, this study explored whether the addition of motor imagery to routine physical therapy reduces the deterioration of quadriceps muscle strength and voluntary activation (VA) as well as other variables related to motor performance in patients after total knee arthroplasty (TKA).

Methods: Twenty-six patients scheduled for TKA were randomized to either Ml practice combined with routine physical therapy group (Mlp) or to a control group receiving physical therapy alone (CON). Mlp consisted of maximal voluntary isometric contraction (MViC) task: $15 \mathrm{~min} /$ day in the hospital, then 5 times/week in their homes for 4 weeks. MViC and VA of quadriceps muscle, knee flexion and extension range of motion, pain level, along with a Timed Up-and-Go Test (TUG) and self-reported measure of physical function (assessed using the Oxford Knee Score questionnaire [OKS]) were evaluated before (PRE) and 1 month after surgery (POST).

Results: Significantly better rehabilitation outcomes were evident on the operated leg for the Mlp group compared to CON: at POST, the Mlp showed lower strength decrease $\left(p=0.012, \eta^{2}=0.237\right)$ and unaltered VA, significantly greater than CON $\left(p=0.014, \eta^{2}=0.227\right)$. There were no significant differences in knee flexion and extension range of motion and pain level $(p>0.05)$. Further, Mlp patients performed better in TUG $\left(p<0.001, \eta^{2}=0.471\right)$ and reported better OKS scores $\left(p=0.005, \eta^{2}=0.280\right)$. The non-operated leg showed no significant differences in any outcomes at POST (all $p>0.05$ ). In addition, multiple linear regression analysis showed that failure of voluntary activation explained $47 \%$ of the quadriceps muscle strength loss, with no significant difference in perceived level of pain.

Conclusion: MI practice, when added to physical therapy, improves both objective and subjective measures of patients' physical function after TKA, and facilitates transfer of MI strength task on functional mobility.

(Continued on next page)
\end{abstract}

\footnotetext{
* Correspondence: n.maffulli@gmul.ac.uk

2Department of Musculoskeletal Disorders, Faculty of Medicine and Surgery, University of Salerno, Salerno, Italy

${ }^{3}$ Centre for Sports and Exercise Medicine, Queen Mary University of London, London, UK

Full list of author information is available at the end of the article
}

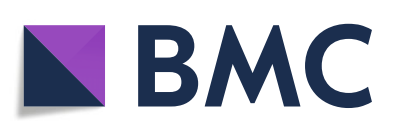

(- The Author(s). 2020 Open Access This article is licensed under a Creative Commons Attribution 4.0 International License, which permits use, sharing, adaptation, distribution and reproduction in any medium or format, as long as you give appropriate credit to the original author(s) and the source, provide a link to the Creative Commons licence, and indicate if changes were made. The images or other third party material in this article are included in the article's Creative Commons licence, unless indicated otherwise in a credit line to the material. If material is not included in the article's Creative Commons licence and your intended use is not permitted by statutory regulation or exceeds the permitted use, you will need to obtain permission directly from the copyright holder. To view a copy of this licence, visit http://creativecommons.org/licenses/by/4.0/. The Creative Commons Public Domain Dedication waiver (http://creativecommons.org/publicdomain/zero/1.0/) applies to the data made available in this article, unless otherwise stated in a credit line to the data. 
(Continued from previous page)

Trial registration: Retrospectively registered on ClinicalTrials.gov NCT03684148

Keywords: Knee osteoarthritis, Total knee replacement, Muscle activation, Cognitive training, Mental simulation, Rehabilitation, Physical function

\section{Introduction}

Osteoarthritis (OA) is a major cause of disability [1, 2]. Total knee arthroplasty (TKA) successfully relieves pain, corrects deformity, and improves function [3, 4]. However, most patients never reach the functional level of the age-matched OA asymptomatic population even years after surgery [5]. Quadriceps strength is a major determinant of general physical function following TKA [6]. In the early post-surgery period, patients experience loss of more than half of their pre-surgery strength [7, 8 ], a likely consequence of the alterations of motor control at a central level induced by surgery [7, 9, 10].

Motor imagery (MI)-i.e., the mental representation of a physical action without overt body movement [11] - is effective in improving motor performance [12, 13]. MI exerts beneficial effects on strength [13] and flexibility [14] in healthy adults; it reduces pain $[15,16]$; and it contributes to the rehabilitation of Parkinson's disease and stroke patients $[17,18]$, though its effects on musculoskeletal patients are equivocal [19]. A recent metaanalysis showed that, when added to routine physical therapy (RPT) in post-injury rehabilitation, MI does not elicit greater benefits on functional mobility, perceived pain, and self-efficiency than RPT alone [19]. However, in older patients following end-stage OA, combining $\mathrm{MI}$ with RPT produces positive effects on motor performance following total hip arthroplasty [20] and TKA [21, 22]. An explanation for these apparently contradictory findings may be ascribed to the different MI intervention approaches used, including sample characteristics (e.g., age and individual ability to undertake MI) and/or the primary outcome measures used.

The efficiency of MI relies on the functional equivalence theory suggesting that, when imagining a movement, similar and identical brain areas are activated as if the movement had actually been performed [11, 23]. Therefore, MI might be a suitable addition to routine rehabilitation in the early-post operative period, especially since TKA patients have long-term impaired mobility and difficulty participating in high-intensity exercise training programmes. A few studies investigated the effects of MI practice in TKA patients [15, 21, 22]. For example, by implementing guided imagery (i.e., cognitive training) in post-rehabilitation, Forward et al. [15] showed positive findings for the management of both pain and anxiety, while Jacobson et al. [22] revealed positive effects on gait velocity and reduction of cortisol levels compared to the RPT group [15, 22]. Adding MI to RPT following TKA surgery significantly increased knee extensor muscles' strength compared to RPT alone [21]. However, none of these studies investigated the possible mechanisms of those positive changes in patients undergoing TKA who undertook MI practice.

Atrophy and a failure of muscle voluntary activation (VA) together explained approximately $85 \%$ of the quadriceps maximal voluntary strength loss [7], of which the relative contribution of VA was nearly twice as great as the relative contribution of muscle atrophy to the observed strength decrease at 1 month post-surgery [7]. Indeed, VA is one of the most investigated proxies of central factors related to strength loss following knee surgery. VA is a major factor in the reduction of maximal force output of the muscle, given a patient's inability to recruit all of the muscle's motor units, or a failure to attain the maximal discharge rate from the recruited motor units [24]. However, little is known regarding whether MI practice can mitigate the decline in VA following TKA.

In this context, we aimed to explore whether MI, when added to routine physical therapy, may reduce deterioration of maximal voluntary isometric strength (MViC), VA, and other variables related to motor performance, such as functional mobility, the range of motion, and self-reported physical function. We hypothesized a greater deterioration of $\mathrm{MViC}, \mathrm{VA}$, and both objective and self-reported measures of physical function in the routine physical therapy group when compared to a MI practice group 1 month post-surgery.

\section{Methods}

\section{Study design}

This was a randomized, controlled, parallel-group intervention trial to evaluate the benefits of adding MI practice to the RPT postoperative rehabilitation programme. Eligible patients were randomly assigned to either an intervention group in which MI practice was combined with RPT (MIp) or to a control group which received RPT alone (CON). Participants were assessed 1 day before surgery and 1 month postoperatively at the Valdoltra Orthopaedic Hospital (Ankaran, Slovenia). Informed consent was obtained from all participants. The study protocol was registered on ClinicalTrials.gov no. NCT03684148. 


\section{Sample size}

Isometric knee extension strength of the OA symptomatic leg was defined as the primary outcome variable for the power analysis. The sample size was calculated based on Hopkins recommendations [25] using an online available spreadsheet (http://sportsci.org/resource/stats/ index.html). The raw mean difference in change (RDC) was calculated based on our pilot study ( $\mathrm{RDC}=0.51$ $\mathrm{Nm} / \mathrm{kg}$; unpublished data). Further, the minimal important difference (MID $=0.19 \mathrm{Nm} / \mathrm{kg}$ ) was calculated as half of between subjects SD as recommended [26]. As in clinical practice, the drop out of participants is common (ageing process, comorbidities, post-surgery complications); we adjusted the originally calculated sample size by following the formula: $\mathrm{N} 1=n /(1-d)$ [27] where $\mathrm{N} 1$ is adjusted sample size, $n$ is the sample size required as per the proposed formula ( $N=10$ per group), and $d$ is the drop-out rate $(d=0.25)$. This resulted in a sample size of 13 participants in each of the two groups (MIp and control). The recruitment of the patients was continued until the target sample size was achieved (26 in total).

\section{Randomization and blinding}

For allocation of the participants, a computer-generated list of random numbers ( 1 or 2 ) was produced using Excel 2016 (Microsoft, Redmond, WA, USA). Group assignment occurred after inclusion criteria were met and prior to the preoperative testing session. Checking for eligibility and group allocation was performed by dedicated medical staff who was not otherwise involved in the clinical management of the patients. Testers were not blinded to group assignment because resources did not permit the hiring of separate personnel for testing and MI practice treatments. The surgeons and the remaining medical staff, including physical therapists, nurses, and administration, were unaware of the group allocation of the patients.

\section{Participants characteristics}

Patients who were scheduled for a primary unilateral TKA by three orthopaedic surgeons at the Valdoltra Orthopaedic Hospital (Ankaran, Slovenia) were consecutively recruited between August 2017 and April 2018. All patients underwent a tricompartmental, cemented TKA using a medial parapatellar approach. Patients were included if they were aged 50 to 85 years, suffered from end-stage $\mathrm{OA}$ of the knee, were scheduled for unilateral TKA, were free from OA or other musculoskeletal problems on the contralateral lower limb, and had not been involved in pre-operative motor imagery treatment. A total of 26 participants successfully completed both (PRE and POST) measurements (for baseline characteristics, see Table 1). The enrolment, randomization, and final analysis

Table 1 Participants' characteristics at baseline

\begin{tabular}{|c|c|c|c|c|c|}
\hline & & Mlp group $(n=13)$ & Control group $(n=13)$ & Drop-outs $(n=8)$ & ANOVA $(p)$ \\
\hline \multicolumn{6}{|l|}{ Demographic characteristics } \\
\hline Age (years) & & $61.69 \pm 5.19$ & $58.85 \pm 5.24$ & $63.88 \pm 4.73$ & 0.096 \\
\hline Sex (men/women) & & $7 / 6$ & $7 / 6$ & $5 / 3$ & \\
\hline BMI $\left(\mathrm{kg} / \mathrm{m}^{2}\right)$ & & $30.54 \pm 4.03$ & $30.15 \pm 1.8$ & $29.12 \pm 3.56$ & 0.615 \\
\hline Total knee arthroplasty, (right side, n) & & $8 / 13$ & $7 / 13$ & $5 / 8$ & \\
\hline Days of hospital stay & & $8.77 \pm 1.74$ & $8.23 \pm 1.83$ & $8.50 \pm 1.6$ & 0.737 \\
\hline \multicolumn{6}{|l|}{ Physical function } \\
\hline \multirow[t]{2}{*}{ MViC extension (Nm/kg) } & Operated leg & $1.37 \pm 0.35$ & $1.51 \pm 0.38$ & $1.49 \pm 0.47$ & 0.657 \\
\hline & Non-operated leg & $1.77 \pm 0.32$ & $1.63 \pm 0.36$ & $1.98 \pm 0.56$ & 0.170 \\
\hline \multirow[t]{2}{*}{ Voluntary muscle activation (\%) } & Operated leg & $80.08 \pm 13.28$ & $80.86 \pm 14.13$ & $87.08 \pm 7.36$ & 0.433 \\
\hline & Non-operated leg & $85.83 \pm 9.48$ & $82.44 \pm 9.65$ & $85.90 \pm 6.79$ & 0.567 \\
\hline \multirow[t]{2}{*}{ Knee flexion (degrees) } & Operated leg & $87.69 \pm 9.66$ & $86.23 \pm 18.08$ & $96.0 \pm 18.24$ & 0.352 \\
\hline & Non-operated leg & $104.23 \pm 8.16$ & $105.54 \pm 13.08$ & $105.75 \pm 12.51$ & 0.940 \\
\hline \multirow[t]{2}{*}{ Knee extension (degrees) } & Operated leg & $4.31 \pm 3.25$ & $3.08 \pm 2.63$ & $3.50 \pm 2.67$ & 0.554 \\
\hline & Non-operated leg & $2.54 \pm 1.81$ & $1.38 \pm 1.56$ & $3.0 \pm 1.77$ & 0.089 \\
\hline \multirow[t]{2}{*}{ VAS score (points) } & Operated leg & $53.85 \pm 12.1$ & $54.62 \pm 14.21$ & $52.5 \pm 18.9$ & 0.950 \\
\hline & Non-operated leg & $8.46 \pm 8.99$ & $14.62 \pm 13.61$ & $9.38 \pm 7.76$ & 0.321 \\
\hline Hand grip strength, dominant arm (kg) & & $39.77 \pm 9.61$ & $36.54 \pm 11.93$ & $43.12 \pm 10.41$ & 0.398 \\
\hline TUG (s) & & $7.48 \pm 1.52$ & $7.57 \pm 1.55$ & $7.78 \pm 1.75$ & 0.914 \\
\hline OKS score (points) & & $21.92 \pm 5.25$ & $22.38 \pm 6.23$ & $26.0 \pm 9.04$ & 0.365 \\
\hline
\end{tabular}


procedures are shown in the CONSORT flow diagram (Fig. 1). Exclusion criteria were participants who were undergoing a revision TKA; those with a body mass index (BMI) greater than $40 \mathrm{~kg} / \mathrm{m}^{2}$; participants who were receiving a bilateral TKA; those with uncontrolled hypertension, diabetes mellitus, a history of any neurological disorder, multiple sclerosis, Parkinson's disease; patients with rheumatoid arthritis or active cancer; previous history of deep vein thrombosis; contralateral knee OA (as defined by pain greater than $4 / 10$ with activity). All procedures were carried out in accordance with the ethical standards of the 1964 Declaration of Helsinki and were approved by the Ethics Committee of Valdoltra Orthopaedic Hospital (approval no. 16/2016).

\section{Interventional programmes}

The RPT and MIp intervention are described using the Template for Intervention Description and Replication (TIDieR) in Table 2 [28].

\section{Hospitalization period}

During hospitalization, all the enrolled patients underwent the same functional exercise-based rehabilitation programme for improving knee range of motion, increasing knee and hip muscle strength, stretching the posterior and anterior aspects of the thigh muscles, preventing thrombosis, and acquiring the most important functional strategies for activities of daily living.

\section{Home-based intervention}

After hospital discharge, both groups were supplied with a physical exercise programme booklet (Supplementary 1) of the same exercises as those performed while in hospital and instructed to perform them at home. Each participant was contacted by phone every other day and monitored for adherence to the prescribed exercise programme.

As the reported placebo effect in psychological outcomes of exercise training is small $(E S=0.20)$ [29] to control the latter and the additional socio-psychological influence of the MI practice instructor on the MI outcomes, we ensured the same conditions for the control group, and spent the same amount of time with each patient (approximately $15 \mathrm{~min}$ per day in the form of verbal communication on site/in hospital or by telephone call/after discharge) regardless of patients' randomization allocation.

\section{Experimental group}

Patients included in the MIp received an additional intervention based on motor imagery beginning immediately after the TKA procedure. Specifically, they were advised to imagine $\mathrm{MViC}$, the same ones as

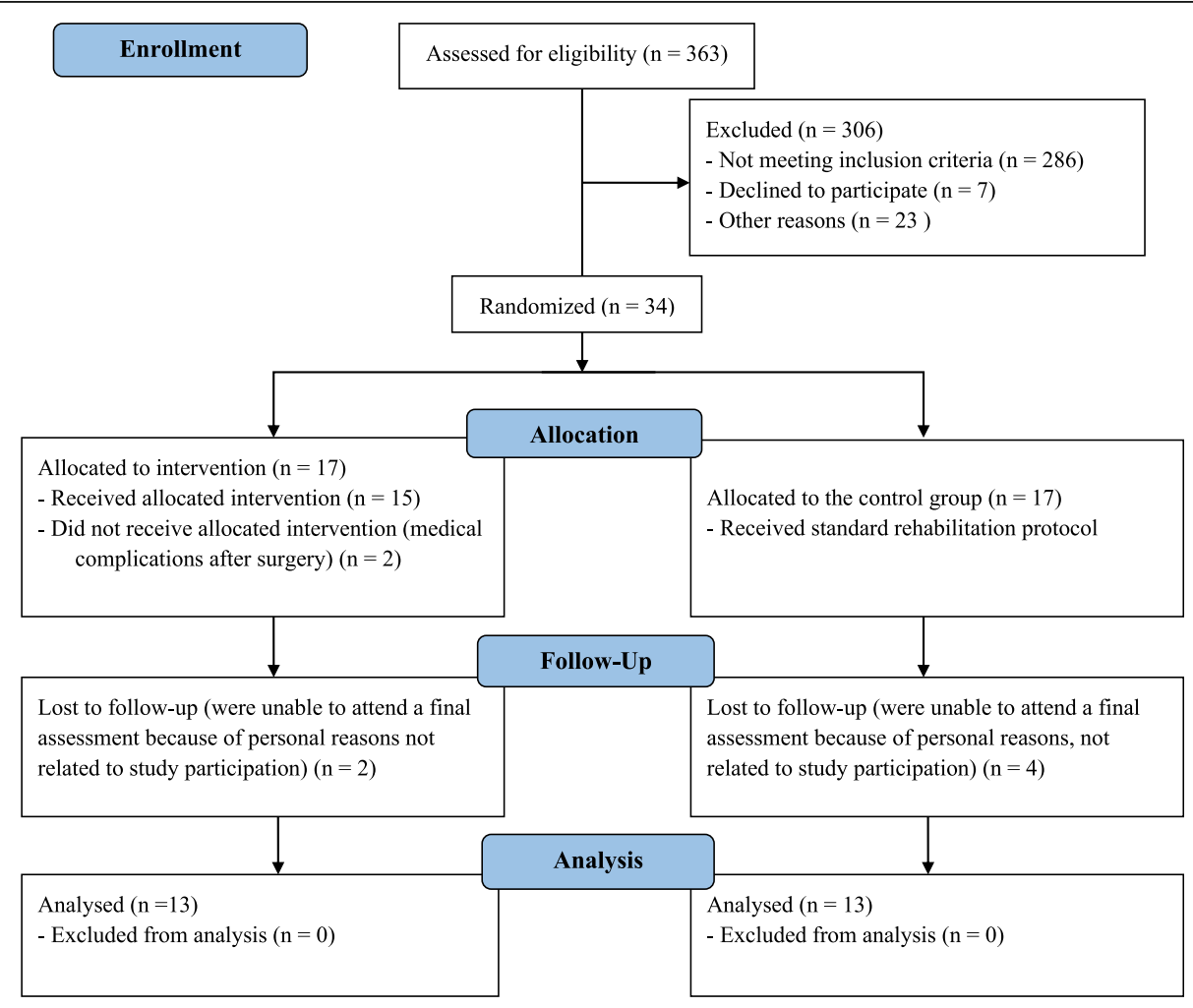

Fig. 1 Flow chart of participant enrolment, randomised group allocation, and final analysis 
Table 2 Study intervention description based on the TIDieR checklist

\begin{tabular}{|c|c|c|c|}
\hline Item & & Experimental group & Control group \\
\hline 1 & Brief name & $\begin{array}{l}\text { Motor imagery practice (Mlp) + routine physical therapy } \\
\text { (RPT) }\end{array}$ & RPT (usual care) alone \\
\hline 2 & Why & \multicolumn{2}{|c|}{$\begin{array}{l}\text { Both interventions were compared directly in OA patients submitted to TKA with following reasons: } \\
\text { 1) TKA patients are unable to undertake conventional strength training in the early period following surgery, whereas } \\
\text { quadriceps strength is a major determinant of general physical function following TKA. } \\
\text { 2) Mlp does not elicit pain or any side effects during practice, nor does it require any additional fees and special } \\
\text { condition, except a quiet space where the trainee/patient can relax and train. } \\
\text { 3) It is assumed that strength decrease following TKA is largely influenced by plasticity in neural drive (central level), } \\
\text { rather than peripheral level. Thus, including MIp in addition to RPT may have a positive effect on maximal voluntary } \\
\text { activation level (a proxy of the central neural drive). } \\
\text { 4) When added to RPT, Mlp might have favourable effects on both task-specific (near transfer) and general physical } \\
\text { function (far transfer), which remains unclear in TKA population. } \\
\text { 5) If so, Mlp might be a suitable adjunct tool to RPT intended to improve rehabilitation of TKA patients, without } \\
\text { additional costs for patients and the health care system. }\end{array}$} \\
\hline
\end{tabular}

3 What: materials

No restriction was placed on materials used (for example: bed, chair, pillow, crutches, steppers, stairs), while the use of additional mechanical (for example: continuous passive motion-only allowed during hospitalization) or electrical therapy devices (for example: neuromuscular stimulation) was avoided.

Hospitalization: patients had one-to-one therapy (Mlp) in sitting position (based on the current patient's physical state). The therapist guided the patient throughout the practice protocol.

After hospital discharge (at home): Mlp practice was delivered by audio mp3 file.
Hospitalization: the patients engaged in conversation with the therapist about their health status, rehabilitation progression based on predefined goals.

After hospital discharge (at home): none in particular, the patients were called by phone (3x per week, on consecutive days) and asked about their subjective health status, treatment adherence and rehabilitation progress.

$4 \quad$ What: procedures

During hospitalization, all the enrolled patients underwent the same functional exercise-based rehabilitation programme aimed to improve knee range of motion, increase knee and hip muscle strength, stretch the posterior and anterior aspect of the thigh muscles, prevent thrombosis, and help acquire the most important functional strategies for activities of daily living. First, the subjects received one daily continuous passive motion (CPM) session (Kinetec Performa), beginning on the second day after TKA (after recovery unit) until discharge (4 to 8 days). The CPM session lasted $45 \mathrm{~min}$, including a 5-min warm-up period. Further, the exercise programme consisted of $60 \mathrm{~min}$ of one-to-one therapy: 5-10 min warm-up and cool-down periods including passive and active stretching of lower limb muscle groups; knee flexion (heel sledge in bed); plantar flexion of ankles (supine); hip abduction and adduction (supine); supine straight leg raises (for the operated leg - the patients used the help of contralateral leg); walking with aids, sit-tostand from chairs of various heights (exercises adopted based on injured knee flexion and pain level); standing calf raises; standing hip flexion and extension; walking up and down the stairs (using crutches and/or handrail), arm raises, and shoulder range of motion.

Mlp additionally performed a mental simulation of maximal isometric contraction only. Patients were instructed to sit on a chair and to imagine the operated leg flexed at $60^{\circ}$ at the knee joint while listening to the therapist or to an audio tape with detailed practice instructions.

$5 \quad$ Who provides

During the hospitalization period, the exercise programme was provided by experienced physical therapist blinded for patients' intervention allocation. Home-based intervention was conducted by patients themselves.

Both interventions were conducted individually in one-to-one sessions (during the hospitalization period), whereas following hospital discharge the patients trained alone.

7 Where Both interventions took place in the hospital (orthopaedic ward programme) and at patients' homes.

8 When and how much

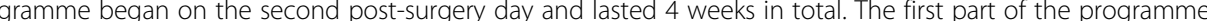
was performed during the hospitalization period ( 6 days on average), whereas after the hospital discharge the patients continued with the allocated intervention at their homes.

All patients, regardless of their allocation to groups, performed an RPT programme 5 times a week, 2 times per day (lasting 45 to $60 \mathrm{~min}$ per session). Each exercise was planned in a progressive manner, meaning:

-Strength exercises: starting with two sets and 10 repetitions per week-then adding 2 repetitions in the second and 3 and 5 more repetitions in the third week and fourth week, respectively;

-Stretching exercises: starting with 3 repetitions and 15-s holds per week-then adding 5 more seconds each week; -Walking exercise: trying to walk for 10 min on level ground — then adding 5 min every week.

Mlp was planned in a progressive manner.

It was performed in two sets of 25 repetitions with 2 min of inter-set rest period, for two weeks, with 10 repetitions added in weeks 3 and 4, respectively. Each MViC repetition was sustained for $5 \mathrm{~s}$ and followed by a 5 -s inter-repetition rest period. Additionally, after every fifth contraction, 
Table 2 Study intervention description based on the TIDieR checklist (Continued)

\begin{tabular}{|c|c|c|c|}
\hline \multicolumn{2}{|c|}{ Item } & Experimental group & Control group \\
\hline & & \multicolumn{2}{|l|}{$\begin{array}{l}\text { participants had } 20 \mathrm{~s} \text { of rest to minimize mental fatigue. } \\
\text { Following } 5 \text { days of Ml practice, the participants were ad- } \\
\text { vised to take a break from Ml for two consecutive days. }\end{array}$} \\
\hline 9 & Tailoring & \multicolumn{2}{|c|}{$\begin{array}{l}\text { The exercise programme content was tailored to each patient's preferences based on their self-perceived level of pain } \\
\text { and current function (mainly knee flexion movement). }\end{array}$} \\
\hline 10 & Modifications & \multicolumn{2}{|l|}{ No modification occurred during the study. } \\
\hline 11 & How well & \multicolumn{2}{|c|}{$\begin{array}{l}\text { Regardless of group assignment, participants were called by principal investigator on a weekly basis and monitored for } \\
\text { adherence to the prescribed treatment for both RPT and Mlp sessions. }\end{array}$} \\
\hline 12 & & $\begin{array}{l}\text { The adherence to the prescribed MI post-rehabilitation } \\
\text { was as high as } 98 \% \text {. }\end{array}$ & $\begin{array}{l}\text { The adherence to RPT was high, } 98 \% \text { and } 96 \% \text { for Mlp } \\
\text { and CON group, respectively. }\end{array}$ \\
\hline
\end{tabular}

during measurement settings. MViC imagery practice was planned in a progressive manner (see Table 2). Briefly, the patients performed two sets of 25 repetitions with $2 \mathrm{~min}$ of inter-set rest periods, for a duration of 2 weeks. To comply with the basic principles of strength training i.e., step-by-step overload and progression, 10 additional trials were added during weeks 3 and 4, respectively. Each $\mathrm{MViC}$ repetition was sustained for $5 \mathrm{~s}$, followed by a 5-s interrepetition rest period. Additionally, after every fifth contraction, the participants had $20 \mathrm{~s}$ of rest. Following 5 days of MI practice, the participants were advised to take a break from MI for two consecutive days. The MI training setup is illustrated in Fig. 2.

\section{Control group}

Patients from the control group underwent the same post-surgery rehabilitation programme described above but did not engage in MI practice.

\section{Assessments}

All measurements were carried out in a separate and quiet room to avoid any external disturbances from the hospital environment. All tests were performed twice, 1 day prior to surgery (PRE) and 1 month post-surgery (POST).

\section{Primary outcomes}

Knee extensor muscles testing Subjects were seated upright and firmly strapped down in a custom-built dynamometer (S2P Ltd., Bled, Slovenia) with their hips and knee flexed at $110^{\circ}$ and at $60^{\circ}$ joint angle. A steel cuff was strapped around the lower leg $\sim 2 \mathrm{~cm}$ above the medial malleoli and connected to a straingauge load cell (Z6FC3-200kg, HBM, Darmstadt, Germany), while arms were crossed at chest level. Individual dynamometer settings were recorded to ensure identical subject positioning at all test sessions (PRE and POST).

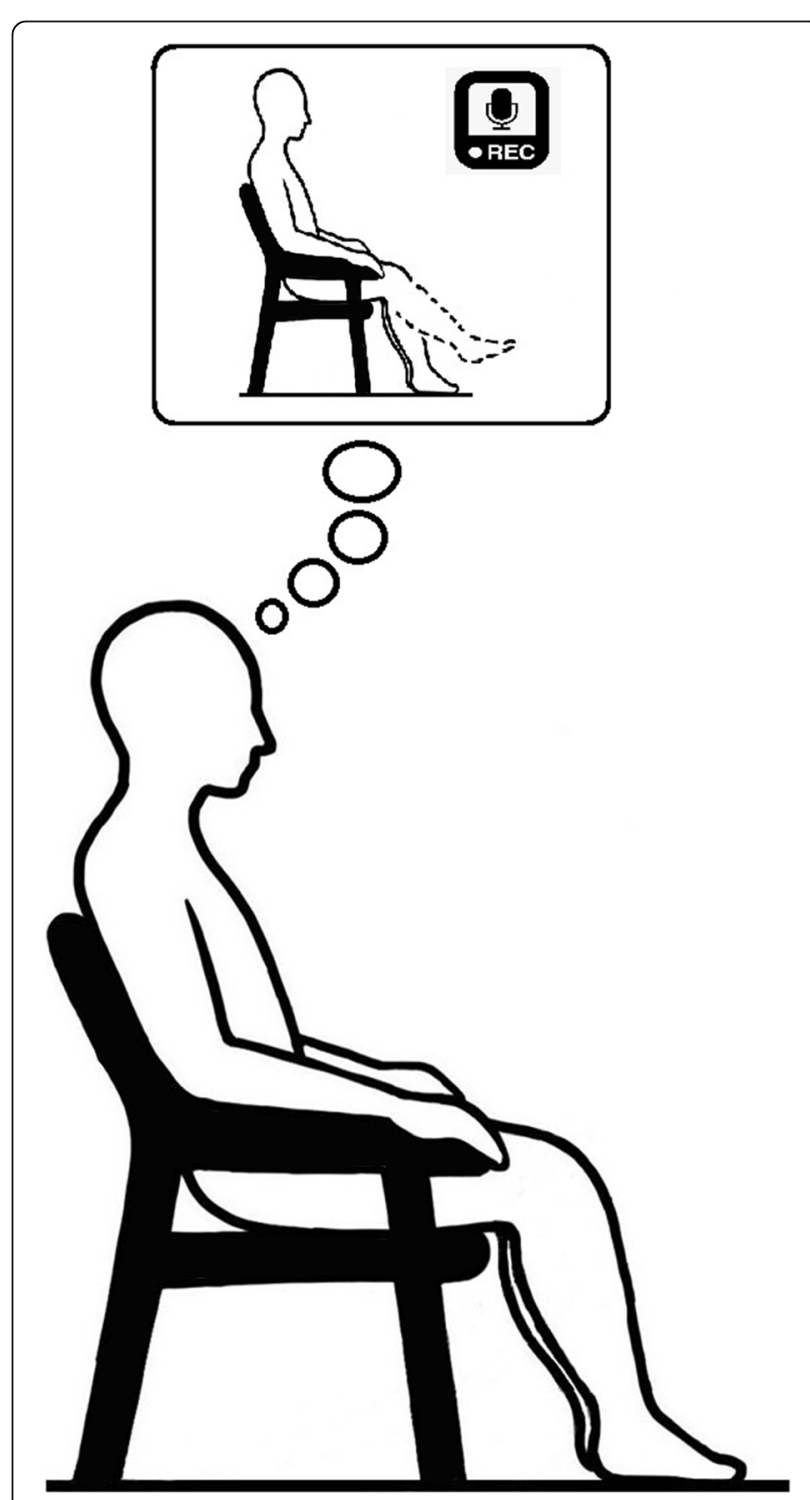

Fig. 2 Motor imagery training setup 
Maximal voluntary isometric strength and voluntary activation of knee extensor muscles Measurement of $\mathrm{MViC}$ of the quadriceps muscle was assessed by using the superimposed double-twitch technique [30]. Each subject performed two submaximal contractions (approximately 50 and $75 \%$ of self-perceived maximal effort) and one maximal voluntary contraction lasting 2 to $3 \mathrm{~s}$ each to warm up the muscle and gain familiarity with the testing procedure. After $3 \mathrm{~min}$ of rest, the subjects were instructed to perform maximal isometric knee extensions, to contract as fast and forcefully as possible and to maintain maximal force exertion until a plateau in force production was reached. Approximately $2 \mathrm{~s}$ into the contraction and $3 \mathrm{~s}$ after, a "supramaximal" double twitch stimulation in the resting muscle was manually delivered by the stimulator. The measurements were conducted using a constant-current electrical stimulator (National Instruments) for stimulating the quadriceps femoris throughout the stimulation of three superficial muscles (rectus femoris, vastus medialis, and vastus lateralis) by self-adhesive $5 \times 5$ and 2 -mm-thick electrodes (dual-stick) located on the proximal and distal portions of individual muscles. Two biphasic, symmetric, and squared electrical impulses (double twitch) of 0.3 ms duration of supramaximal intensity were used at an interval of $10 \mathrm{~ms}$. During the actual measurement, the knee was additionally fixed over the medial and lateral epicondyles of the femur and the hip (Fig. 3). Strong verbal encouragement and visual feedback of the dynamometer force response were provided during all trials. All MViC trials (up to three per subject) were separated by $2 \mathrm{~min}$ of rest. Trials with a visible initial countermovement (i.e., drop of the force above 0 value) were discarded. The trial with the highest superimposed peak force was selected as representative of MViC. Voluntary muscle activation was calculated according to the formula proposed by Strojnik and Komi [31]:

$$
\mathrm{VA}(\%)=1-\left(\frac{\mathrm{D} *\left(\frac{F \mathrm{Stim}}{\text { FM ViC }}\right)}{\text { FStimRest }}\right) * 100
$$

where $D$ is the difference between force at stimulation $\left(F_{\text {Stim }}\right)$ and the force peak evoked by stimulation onto the $\mathrm{MViC}, F_{\mathrm{MViC}}$ is force at $\mathrm{MVC}$, and $F_{\text {StimRest }}$ is force achieved due to stimulation in the potentiated resting muscle.

MViC was normalized to body mass, as maximal strength is a variable dependent on body size [32].

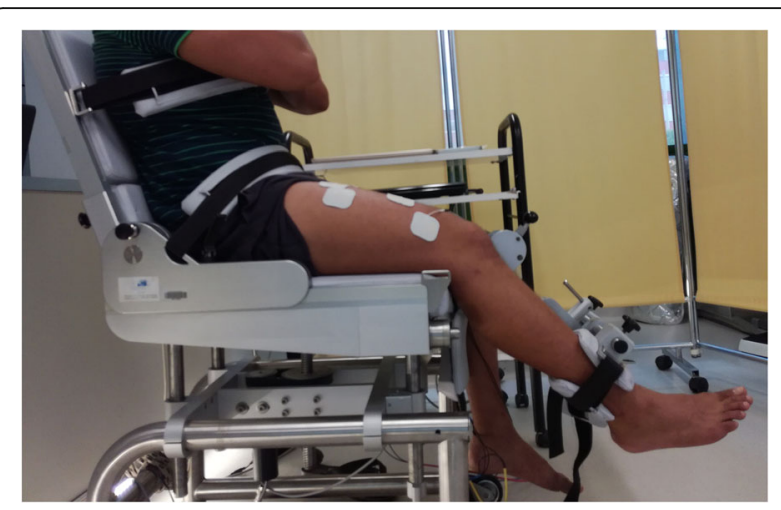

Fig. 3 Experimental setup for the measurement of isometric strength and voluntary activation of the quadriceps femoris muscle

\section{Secondary outcomes}

Timed Up-and-Go Test The TUG test was administered to quantify the functional mobility of patients [33]. The patients were asked to rise from the chair (seat height $46 \mathrm{~cm}$ ), walk around an obstacle that was $3 \mathrm{~m}$ away, turn around, and return to take a seat as quickly and safely as possible. Patients were instructed to walk as quickly as they could while feeling both safe and comfortable. A stopwatch was used to measure the time to complete the TUG within the nearest onehundredth of a second. The TUG measures mobility in older adults with excellent test-retest reliability (intraclass correlation coefficient $[\mathrm{ICC}]=0.97$ ) [34]. A practice trial was given, and then two timed trials were recorded and averaged [20].

Range of motion Knee ROM was measured using a standard long-arm goniometer, as previously reported [35]. The axis of the goniometer was aligned with the centre of the lateral epicondyle of the femur. The distal arm of the goniometer was aligned with the lateral malleolus and the proximal arm was aligned with the greater trochanter of the femur. To determine knee flexion ROM, patients were supine and asked to actively slide the heel towards the buttocks. The angle of maximal active knee flexion was measured. Knee extension ROM was also assessed while supine, with the patient's heel propped off the treatment table on a $15-\mathrm{cm}$-thick hard foam pad. Subjects were asked to activate the quadriceps, extending the knee. The angle of the maximal extension was recorded. Positive values were used to indicate a position of flexion at maximal knee extension, and negative numbers were used to represent hyperextension. Knee ROM measured in patients with knee OA has adequate reliability with a coefficient of 0.96 for flexion and 0.81 for extension [36]. 
Knee pain A numeric rating scale was used to quantify knee pain during rest as well as during burstsuperimposition testing. Subjects were asked to verbally rate the pain in and around the knee during the burst superimposition test on a scale from 0 to 100 , with 0 representing no pain and 100 representing the worst pain imaginable [37].

Maximal grip strength Maximal grip strength was measured bilaterally with a portable Jamar Hydraulic Hand Dynamometer (Sammons Preston, Rolyan, Bolingbrook, IL, USA). In accordance with American Society of Hand Therapy recommendations, subjects were seated with their shoulders in $0^{\circ}$ abduction and neutral rotation, their elbows in $90^{\circ}$ of flexion, and their forearms in neutral pronation/supination. The average of three and two maximal repetitions was used for further analysis.

Self-reported physical function The Oxford Knee Score (OKS) questionnaire was used to evaluate the selfreported physical function of patients with different knee pathologies and following TKA surgery [38]. Each of the 12 questions on the OKS is scored in the same way with the score decreasing as the reported symptoms increase (i.e., become worse), that is the highest result of 60 points represents no symptoms at all.

\section{Data analysis}

The data were analysed with IBM SPSS Statistics 24.0 software for Windows (SPSS Inc., Chicago, IL, USA). Normality of distribution was confirmed by visual inspection and using the Shapiro-Wilk test, while the homogeneity of variances was tested using Levene's test for all dependent variables. To minimise the results of interpretation bias due to patients lost to follow-up, three-fold analysis including the initial comparison of three groups (MIp vs CON vs Drop-outs), intention-totreat and per-protocol analysis were utilised as recommended [31, 32]. Therefore, a one-way analysis of variance (ANOVA) was used to examine whether participants who completed the study protocol differed from those who did not (i.e., dropouts $N=8$ ). Further, mixed-effect models were used to examine the primary and secondary hypotheses using the intention-to-treat approach, allowing us to incorporate all patients who were originally randomly assigned to their groups (including data from patients with missing values). The maximum likelihood estimation method for missing values was used in the mixed effects models. Missing data ( $N=\mathrm{O}$ from baseline; $N=8$ from final measurements) was not imputed. In all models, the fixed factor was group assignment (MIp vs. CON), with two-time points (PRE vs. POST). Interactions were tested by a two-way analysis of variance (ANOVA) where the group
(MIp and CON) was used as the between-subject factor and time (PRE and POST measurements) as the withinsubject factor. In case of significance,post hoc comparisons were performed. In addition, we performed multiple linear regression analysis to investigate the contribution of changes in voluntary activation and pain to the changes in quadriceps strength. Further, magnitude-based inferences were determined by quantifying the chances that true differences in comparisons were greater, similar to, or smaller than the smallest significant difference and interpreted qualitatively as most unlikely $=<0.5 \%$; very unlikely $=0.5-5 \%$; unlikely $=5-25 \%$; possibly $=25-75 \%$; likely $=$ 75-95\%; very likely $=95-99.5 \%$; most likely $=>99.5 \%$ [39]. Statistical significance was set at the level of $p<0.05$ [39].

\section{Results}

\section{Study population}

Three hundred sixty-three patients scheduled for TKA at Valdoltra Orthopaedic Hospital were assessed for eligibility. Three hundred six patients were excluded: 286 did not satisfy the inclusion criteria, 7 patients declined to participate, and 23 patients were excluded for various other reasons (pre-operative comorbidities; inability to attend for post-operative measurements). Therefore, 26 patients (14 males and 12 females) were enrolled in the study (details depicted in Fig. 1). There were no differences between groups in baseline demographic data $(p>$ 0.05 , Table 1). No patient reported adverse events resulting from participation in the study. The adherence to prescribed post-rehabilitation was high (98\%). Functional outcome data did not violate normality of distribution as assessed by the Shapiro-Wilk test (all $p \geq 0.071$ ). Furthermore, the independent-samples $t$ test showed no significant differences between the intervention and control groups in any outcome parameter at baseline.

Overall findings regarding performance and selfreported measures of MI practice and control groups before and 1 month after surgery are presented in Tables 3 and 4.

\section{Knee extensor muscles isometric strength and voluntary activation \\ Operated leg}

Both MIp and CON groups had significantly lower knee extensors strength of the operated leg at 1 month following surgery, when compared to PRE $\left(F_{1,24}=146.551, p<0.001, \eta^{2}=0.859\right)$. There was a significant time $\times$ group interaction effect $\left(F_{1,24}=\right.$ 9.215, $\left.p=0.006, \eta^{2}=0.277\right)$. Post hoc analysis showed that the MIp experienced a significantly lower decrease in strength compared to the CON group $(-42.32 \pm 15.20 \%$ vs. $-62.46 \pm 15.72 \%, p=$ 0.003) (Fig. 4). 


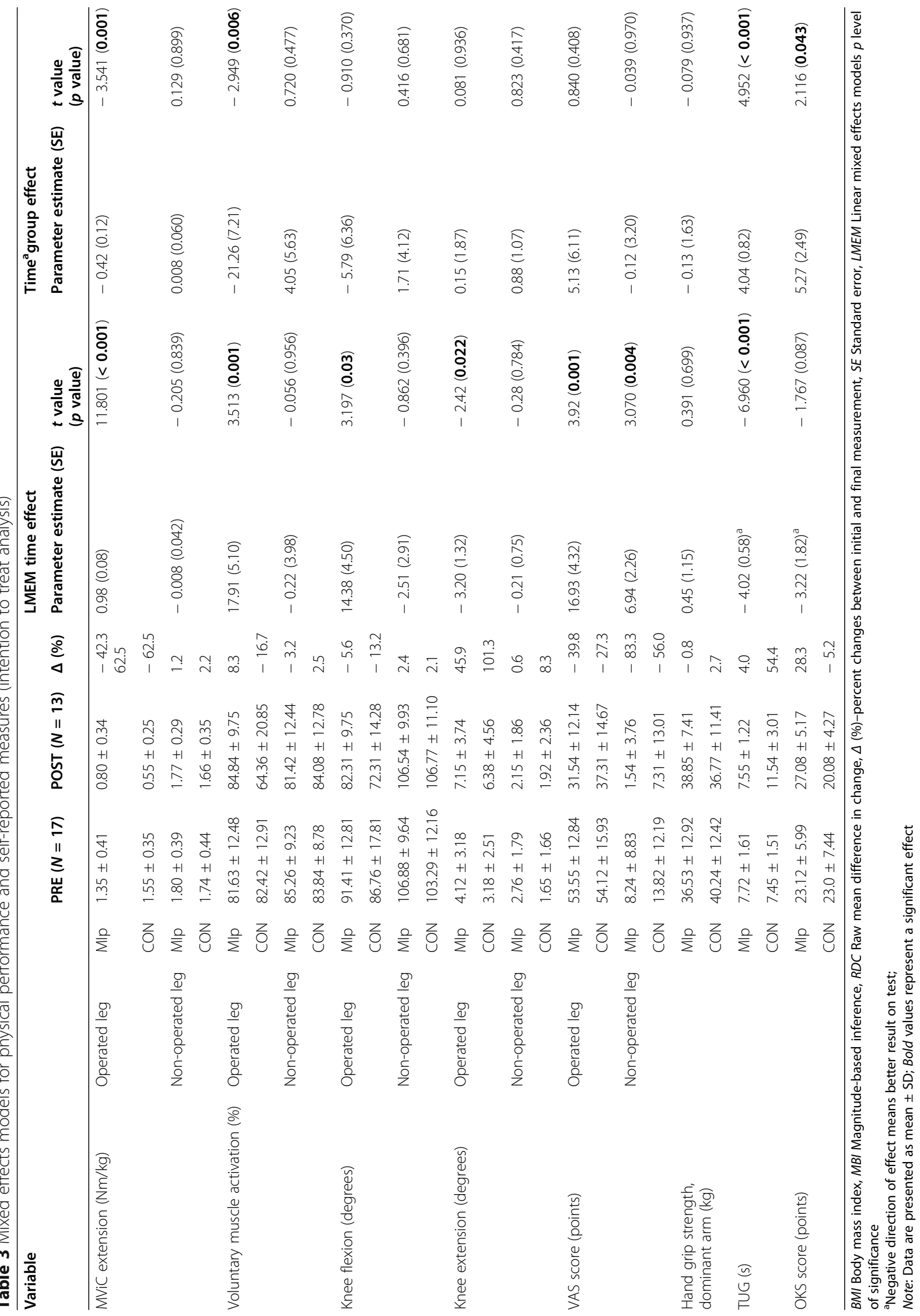


Table 4 Performance and self-reported measures of motor imagery practice (Mip) and control (CON) groups before and 1 month after surgery (per protocol analysis)

\begin{tabular}{|c|c|c|c|c|c|c|}
\hline Variable & & & PRE $(N=13)$ & POST $(N=13)$ & $\mathrm{RDC}(95 \% \mathrm{Cl})$ & $\mathrm{MBI}$ \\
\hline \multirow[t]{4}{*}{ MViC extension ( $\mathrm{Nm} / \mathrm{kg})$} & \multirow[t]{2}{*}{ Operated leg } & Mlp & $1.37 \pm 0.35$ & $0.80 \pm 0.34$ & \multirow[t]{2}{*}{$0.39(0.03,0.75)$} & \multirow[t]{2}{*}{ Likely beneficial } \\
\hline & & CON & $1.51 \pm 0.38$ & $0.55 \pm 0.25$ & & \\
\hline & \multirow[t]{2}{*}{ Non-operated leg } & Mlp & $1.77 \pm 0.32$ & $1.77 \pm 0.29$ & \multirow[t]{2}{*}{$-0.03(-0.39,0.33)$} & \multirow[t]{2}{*}{ Possibly negative } \\
\hline & & CON & $1.63 \pm 0.36$ & $1.66 \pm 0.35$ & & \\
\hline \multirow[t]{4}{*}{ Voluntary muscle activation (\%) } & \multirow[t]{2}{*}{ Operated leg } & Mlp & $80.08 \pm 13.28$ & $84.84 \pm 9.75$ & \multirow[t]{2}{*}{$21.26(4.90,37.62)$} & \multirow[t]{2}{*}{ Very likely beneficial } \\
\hline & & CON & $80.86 \pm 14.13$ & $64.36 \pm 20.85$ & & \\
\hline & \multirow[t]{2}{*}{ Non-operated leg } & Mlp & $85.83 \pm 9.48$ & $81.42 \pm 12.44$ & \multirow[t]{2}{*}{$-6.05(-18.22,6.12)$} & \multirow[t]{2}{*}{ Unlikely negative } \\
\hline & & CON & $82.44 \pm 9.65$ & $84.08 \pm 12.78$ & & \\
\hline \multirow[t]{4}{*}{ Knee flexion (degrees) } & \multirow[t]{2}{*}{ Operated leg } & Mlp & $87.69 \pm 9.66$ & $82.31 \pm 9.75$ & \multirow[t]{2}{*}{$8.54(-6.04,23.12)$} & \multirow[t]{2}{*}{ Likely beneficial } \\
\hline & & CON & $86.23 \pm 18.08$ & $72.31 \pm 14.28$ & & \\
\hline & \multirow[t]{2}{*}{ Non-operated leg } & Mlp & $104.23 \pm 8.16$ & $106.54 \pm 9.93$ & \multirow[t]{2}{*}{$1.08(-10.57,12.73)$} & \multirow[t]{2}{*}{ Possibly beneficial } \\
\hline & & CON & $105.54 \pm 13.08$ & $106.77 \pm 11.10$ & & \\
\hline \multirow[t]{4}{*}{ Knee extension (degrees) } & \multirow[t]{2}{*}{ Operated leg } & Mlp & $4.31 \pm 3.25$ & $7.15 \pm 3.74$ & \multirow[t]{2}{*}{$-0.46(-4.39,3.47)$} & \multirow[t]{2}{*}{ Possibly negative } \\
\hline & & CON & $3.08 \pm 2.63$ & $6.38 \pm 4.56$ & & \\
\hline & \multirow[t]{2}{*}{ Non-operated leg } & Mlp & $2.54 \pm 1.81$ & $2.15 \pm 1.86$ & \multirow[t]{2}{*}{$-0.93(-3.02,1.16)$} & \multirow[t]{2}{*}{ Unlikely negative } \\
\hline & & CON & $1.38 \pm 1.56$ & $1.92 \pm 2.36$ & & \\
\hline \multirow[t]{4}{*}{ VAS score (points) } & \multirow[t]{2}{*}{ Operated leg } & Mlp & $53.85 \pm 12.1$ & $31.54 \pm 12.14$ & \multirow[t]{2}{*}{$-5.00(-19.49,9.49)$} & \multirow[t]{2}{*}{ Unlikely negative } \\
\hline & & CON & $54.62 \pm 14.21$ & $37.31 \pm 14.67$ & & \\
\hline & Non-operated leg & Mlp & $8.46 \pm 8.99$ & $1.54 \pm 3.76$ & $-0.39(-11.91,11.13)$ & Possibly negative \\
\hline & & CON & $14.62 \pm 13.61$ & $7.31 \pm 13.01$ & & \\
\hline Hand grip strength, dominant arm (kg) & & Mlp & $39.77 \pm 9.61$ & $38.85 \pm 7.41$ & $-1.15(-12.29,9.99)$ & Possibly negative \\
\hline & & CON & $36.54 \pm 11.93$ & $36.77 \pm 11.41$ & & \\
\hline TUG (s) & & Mlp & $7.48 \pm 1.52$ & $7.55 \pm 1.22$ & $-3.90(-6.02,-1.78)^{*}$ & Most likely beneficial \\
\hline & & CON & $7.57 \pm 1.55$ & $11.54 \pm 3.01$ & & \\
\hline OKS score (points) & & Mlp & $21.92 \pm 5.25$ & $27.08 \pm 5.17$ & $7.46(1.72,13.20)$ & Very likely beneficial \\
\hline & & CON & $22.38 \pm 6.23$ & $20.08 \pm 4.27$ & & \\
\hline
\end{tabular}

$B M I$ Body mass index, $M B I$ Magnitude-based inference, RDC Raw mean difference in change

${ }^{*}$ Negative direction of effect means better result on test

Voluntary activation of knee extensor muscles was significantly lower in the CON group at post-surgery, when compared to PRE $(-16.66 \pm 38.61, p=0.036)$. A non-significant main effect was observed $\left(F_{1,24}=\right.$ 2.149, $\left.p=0.156, \eta^{2}=0.082\right)$, with significant time $\times$ group interaction effect $\left(F_{1,24}=7.042, p=0.014, \eta^{2}=\right.$ 0.227). Post hoc analysis showed that the MIp maintain their pre-operative levels of voluntary activation $(8.28 \pm 18.84 \%, p=0.246)$, while significant differences were observed between groups at post-surgery $(p=0.047)$ (Fig. 4).

\section{Non-operated leg}

Both MIp and CON groups showed no significant changes in the strength of the non-operated leg when compared to PRE (both $p \leq 0.551)$. There were neither significant main $(p=0.551)$ nor interaction effects $(p=$ 0.833) (Fig. 4).The same was found for voluntary muscle activation of the non-operated leg, which was not significantly altered post-surgery (both $\leq 0.423$ ). There were neither significant main $(p=0.661)$ nor interaction effects $(p=0.341)$ (Fig. 4).

\section{Knee flexion and extension range of motion Operated leg}

There was a significant main effect for both flexion $\left(F_{1,24}\right.$ $\left.=10.352, p=0.004, \eta^{2}=0.301\right)$ and extension $\left(F_{1,24}=\right.$ 8.999, $\left.p=0.006, \eta^{2}=0.273\right)$. There were no significant time $\times$ group interaction effect for both flexion $(p=$ $0.168)$ and extension $(p=0.824)$ of the operated leg at 1 month following surgery.

\section{Non-operated leg}

Both MIp and CON groups showed no significant changes in flexion or extension of the non-operated leg when compared to PRE (both $p \leq 0.668$ ). There were 


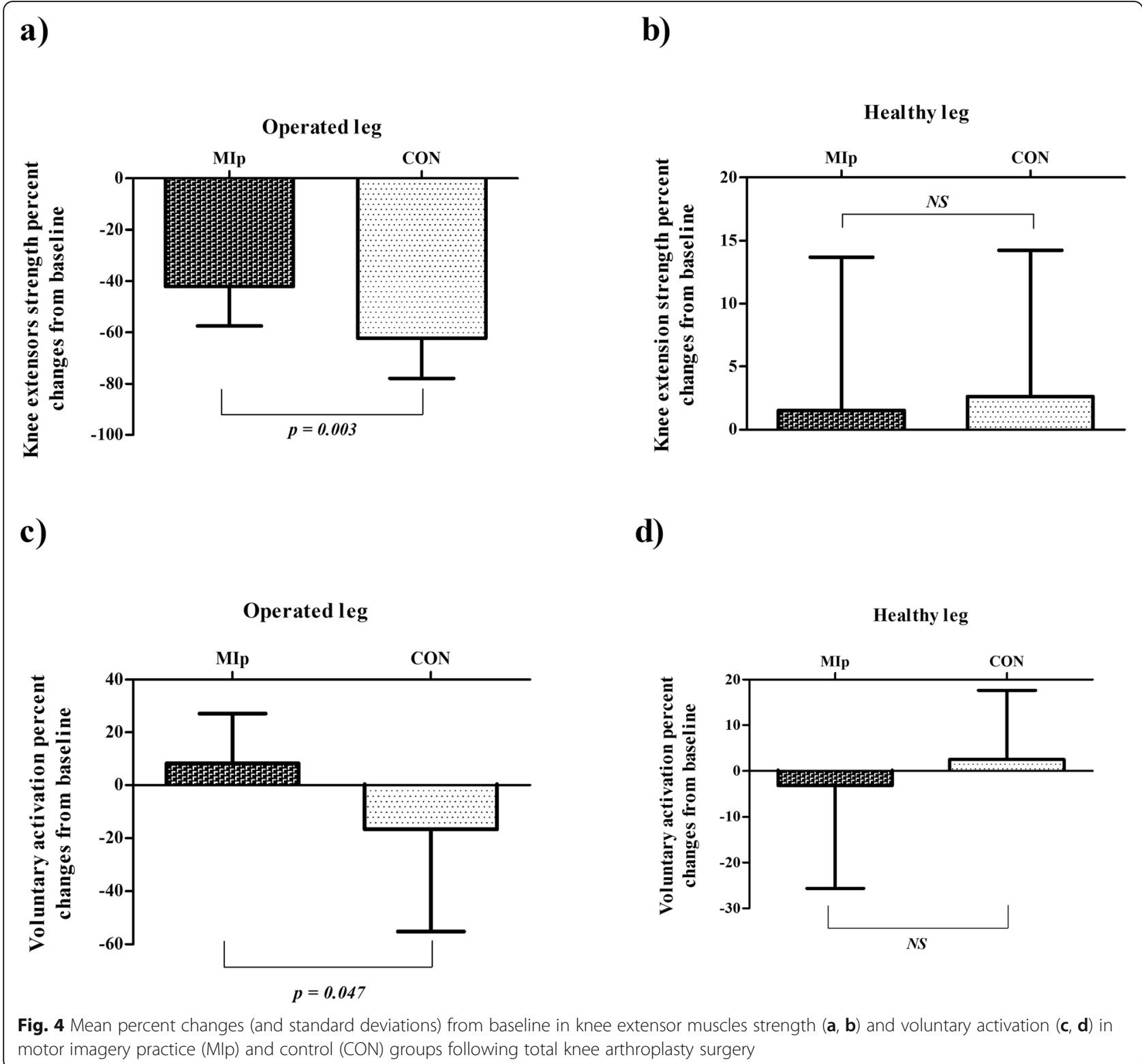

neither significant main (both $p \leq 0.417$ ) nor interaction effects $(p=0.430)$.

\section{Timed Up-and-Go Test (TUG)}

There was a significant time $\times$ group interaction effect $\left(F_{1,24}=21.355, p<0.001, \eta^{2}=0.471\right)$. Post hoc analysis showed that the MIp maintained their level of performance between pre- and post-surgery $(+4.02$ $\pm 24.55 \%, p=0.888$ ), while there was a significant decrease in the CON group, displayed as more time taken for the TUG test at post-surgery $(+54.38 \pm$ $38.17 \%, p<0.001)$. In addition, a significant difference between groups was observed post-surgery $(p=$ 0.001) (Fig. 5).

\section{Knee pain}

Both the MIp and CON groups showed significantly lower knee pain in the operated (MIp - $39.79 \pm 21.19$; CON $-27.29 \pm 32.6$; both $p<0.05)$ and non-operated leg (MIp - 83.33 \pm 35.63 ; CON $-56.0 \pm 49.71$; both $p<$ $0.05)$ at 1 month following surgery, when compared to PRE. However, there were no significant interaction effects (both $p \leq 0.455$ ).

\section{Maximal grip strength}

Both MIp and CON groups showed no significant changes in grip strength when compared to $\operatorname{PRE}(p=$ $0.456)$. There were neither significant main $(p=0.624)$ nor interaction effects $(p=0.416)$. 


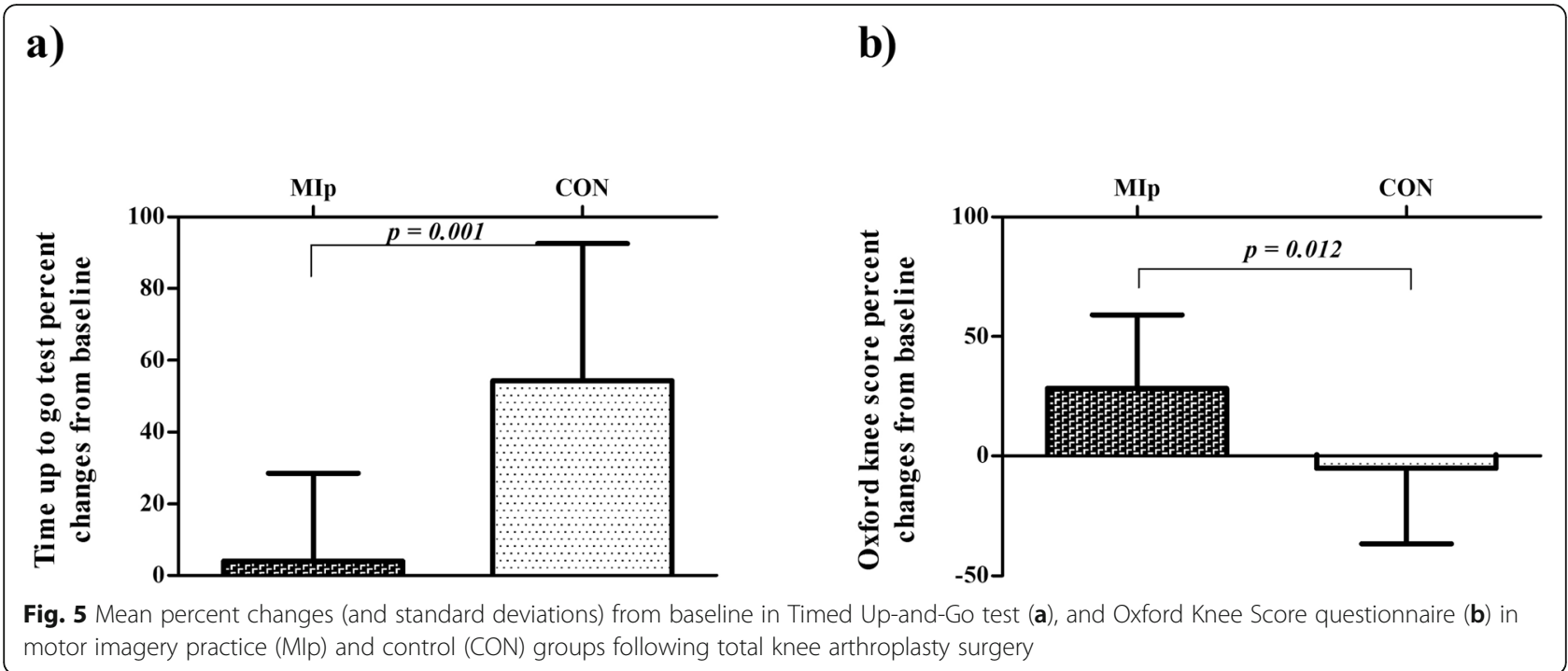

\section{Oxford Knee Score (OKS) questionnaire}

There was significant time $\times$ group interaction effect $\left(F_{1,24}=9.254, p=0.005, \eta^{2}=0.280\right)$. Post hoc analysis showed that the MIp experienced significant increase in OKS score between pre- and post-surgery $(+28.26 \pm$ $30.86 \%, p=0.018$ ), with no significant deterioration in the CON group $(-5.16 \pm 31.52 \%, p=0.163)$. In addition, a significant difference between groups was observed post-surgery ( $p=0.012)$ (Fig. 5).

\section{Regression analysis}

Multiple regression analysis revealed that delta change in voluntary muscle activation and delta change in perceived pain explained $47.3 \%$ of the relative change in the operated leg quadriceps muscle strength $\left(r^{2}=0.474, p=\right.$ $0.001)$. However, voluntary muscle activation alone accounted for $47 \%$ of the observed strength loss of the quadriceps $\left(r^{2}=0.470, p<0.001\right)$ (Fig. 6), while pain accounted for $2.6 \%$ only $\left(r^{2}=0.026, p=0.428\right)$.

\section{Discussion}

This study compared the short-term effects of MI practice in addition to routine physical therapy on VA and other objective and subjective measures related to motor performance in TKA patients. The major findings were that the patients in the MIp maintained pre-surgery levels of VA, experienced less deterioration of quadriceps muscle strength and functional mobility, and had significantly greater self-reported scores in physical function at POST when compared to controls. Further, there were no observed differences in knee range of motion or perceived level of pain. Also, MI practice intervention did not affect the motor performance of the nonoperated leg in any of the variables assessed, suggesting that there were no contralateral limb effects. In addition, multiple linear regression analysis showed that the failure of VA explained $47 \%$ of the quadriceps muscle strength loss, with no significant contribution of the perceived level of pain.

Recovery of quadriceps muscle strength has recently received considerable attention, being a major determinant of general physical function following a TKA $[6,40]$. Accordingly, in the early acute post-surgery period a variety of factors could alter the quadriceps muscle function, including joint damage [41, 42], pain [43], use of a tourniquet during operative procedure [44], inflammation [45], and post-operative knee swelling [8] eventually inducing arthrogenic muscle inhibition [46]. Quadriceps arthrogenic inhibition is commonly assessed by VA measurement and plays a significant role in quadriceps weakness, explaining approximately $60 \%$ of quadriceps muscle strength loss from pre-to-post surgery [7, 47].

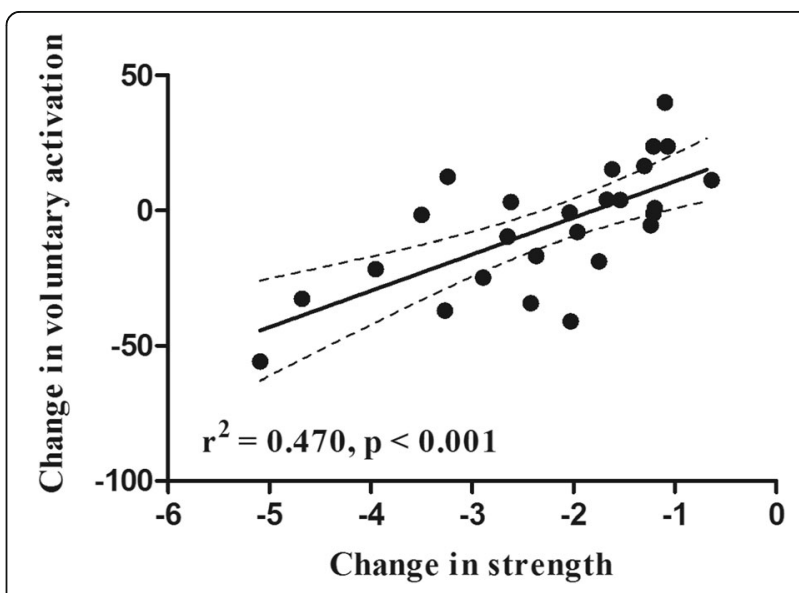

Fig. 6 Linear regression analysis of the contribution of the change in voluntary activation to the change in the strength of the quadriceps muscle of the operated leg 
Similar to previous studies [7, 48], voluntary activation explained nearly half of the quadriceps muscle strength loss. Hence, our hypothesis that MI practice can modify proxies of central factors of movement control was confirmed, demonstrating significant negative alterations of VA in controls only (-16.7\%), while MIp showed a nonsignificant increase of $8.3 \%$ on average. Although quadriceps strength of the operated leg was significantly altered following surgery, the MIp maintained greater preoperative strength compared to the control, at 1 month post-surgery. This could be directly related to preserved muscle activation. This magnitude of difference in response is similar to that reported in previous studies (Table 5) $[21,49,50]$. For example, $26.9 \%$ and $19.9 \%$ of difference favouring high-intensity rehabilitation vs. lowintensity rehabilitation [49] and neuromuscular electrical stimulation (NmES) vs. RPT [50] were found in TKA patients, respectively. Moreover, Moukarzel et al. [21] investigated the effects of MI practice as an adjunct tool to combined NmES and RPT rehabilitation: the MI group gained 26.9\% more strength than the control group [21]. The latter results support previous findings that combining the MI with NmES in addition to common physical therapy is beneficial to evoking re-learning of the motor task in stroke patients compared to NmES only [51, 52]. The provision of somatosensory inputs during MI influences motor performance improvement thanks to motor cortex plasticity [52], in a fashion similar to the actual execution of the movement [53]. While the methodological heterogeneity of the aforementioned studies is evident (i.e., in intervention applied to the experimental and/or control group and the time of baseline evaluation), our results showed comparable magnitude and direction of the effect of MI practice on the alleviation of strength loss in the early post-surgery period of TKA patients. Also, the central mechanisms of MI practice effectiveness were confirmed. Therefore, future studies should use a holistic approach and combine MI with NmES in addition to RPT.

MI exerts positive effects on strength improvements following musculoskeletal injuries [54] and/or surgeries [21]. During mental simulation of movement, similar neurophysiological processes are activated as during actual movement execution $[55,56]$. Thus, without mechanical stimulus on the musculoskeletal system, the underlying mechanism of those changes might be of neural origin only $[57,58]$. Indeed, MI practice induces cortical reorganization [59]. Further, it evokes movement-related cortical potentials, enhancing corticospinal excitability and muscular activity, which that consequently leads to increased muscle force output [13, 60-62]. To the best of our knowledge, only one previous study tested the hypothesis that MI training increases voluntary neural drive to task-oriented muscle action assessed by the twitch interpolation technique. Following 8 weeks of isometric strength training of the elbow flexor muscles, imagined isometric training or active control group, revealed significant pre- to post-strength improvement in all groups, without any significant alterations in VA level.

Compared to our study, previously reported nonsignificant changes in voluntary drive might be ascribed to differences in the studied population (healthy young vs. older adults) and higher prior study levels of VA in trained muscle $(96.2 \pm 0.5 \%$ vs. MIp $80.08 \pm 13.28 \%$ and CON $80.86 \pm 14.13 \%)$. It is possible that MI practice does not provide enough stimuli to induce significant changes in the neural drive in healthy young adults with already high values of VA. On the contrary, it exerts beneficial effects in an older symptomatic population with chronically impaired knee function.

Table 5 Comparison of published studies on operated leg quadriceps strength recovery in patients undergoing TKA before and 1 month after surgery

\begin{tabular}{|c|c|c|c|c|c|c|c|c|}
\hline \multirow[t]{2}{*}{ Study } & \multirow[t]{2}{*}{ Test mode } & \multirow{2}{*}{$\begin{array}{l}\text { Time } \\
\text { point }\end{array}$} & \multirow{2}{*}{$\begin{array}{l}\text { Types of } \\
\text { intervention }\end{array}$} & \multicolumn{5}{|l|}{ Groups } \\
\hline & & & & PRE & POST & $\begin{array}{l}\text { Percent of } \\
\text { change }\end{array}$ & RDC (95\% Cl) & MBI \\
\hline \multirow[t]{2}{*}{ Bade and Stevens } & \multirow{2}{*}{$\begin{array}{l}\text { Isometric } 60^{\circ} \\
(\mathrm{Nm} / \mathrm{kg})\end{array}$} & \multirow[t]{2}{*}{3.5 weeks } & HIRT & $1.3 \pm 0.5$ & $1.0 \pm 0.3$ & -23.1 & \multirow[t]{2}{*}{$0.30(-0.11,0.71)$} & \multirow[t]{2}{*}{ Possibly beneficial } \\
\hline & & & LIRT & $1.2 \pm 0.4$ & $0.6 \pm 0.2$ & -50.0 & & \\
\hline \multirow[t]{2}{*}{ Stevens-Lapsley et al } & \multirow{2}{*}{$\begin{array}{l}\text { Isometric } 60^{\circ} \\
(\mathrm{Nm} / \mathrm{kg})\end{array}$} & \multirow[t]{2}{*}{3.5 weeks } & NmES & $1.33 \pm 0.57$ & $0.93 \pm 0.41$ & -30.1 & \multirow[t]{2}{*}{$0.26(0.02,0.50)$} & \multirow[t]{2}{*}{ Possibly beneficial } \\
\hline & & & Usual care & $1.32 \pm 0.49$ & $0.66 \pm 0.24$ & -50.0 & & \\
\hline \multirow[t]{2}{*}{ Moukarzel et al. } & \multirow{2}{*}{$\begin{array}{l}\text { Isometric HHD } \\
\text { (Nm/BMI) }\end{array}$} & \multirow[t]{2}{*}{4 weeks } & Mlp & $6.09 \pm 0.55$ & $13.30 \pm 0.87$ & +118.4 & \multirow[t]{2}{*}{$1.59(0.90,2.28)$} & \multirow[t]{2}{*}{ Most likely beneficial } \\
\hline & & & Usual care & $6.14 \pm 0.46$ & $11.76 \pm 0.82$ & +91.5 & & \\
\hline \multirow[t]{2}{*}{ Current study } & \multirow{2}{*}{$\begin{array}{l}\text { Isometric } 60^{\circ} \\
(\mathrm{Nm} / \mathrm{kg})\end{array}$} & \multirow[t]{2}{*}{4 weeks } & Mlp & $1.37 \pm 0.35$ & $0.80 \pm 0.34$ & -42.32 & \multirow[t]{2}{*}{$0.39(0.03,0.75)$} & \multirow[t]{2}{*}{ Likely beneficial } \\
\hline & & & Usual care & $1.51 \pm 0.38$ & $0.55 \pm 0.25$ & -62.46 & & \\
\hline
\end{tabular}

HHD Hand-held dynamometer, HIRT High-intensity resistance training, LIRT Low-intensity resistance training, MBI Magnitude-based inference, MIp Motor imagery practice group, NmES Neuromuscular electrical stimulation, RDC Raw mean difference in change 
Considering the range of motion and knee pain, there were no significant changes following MI practice, in contrast to the findings of a recent study investigating MI training in TKA patients rehabilitation [21]. While we were concentrated on strength only, Moukarzel et al. [21] designed MI practice with several MI exercises, focusing on three different objectives: i.e., (i) knee pain management, (ii) flexibility, and (iii) quadriceps strength [21]. The patients demonstrated only training-specific changes (i.e., alleviated pain, enhanced range of motion, and quadriceps strength), without effects that went beyond the trained task (e.g., functional mobility assessed by TUG test or knee swelling). The positive association of strength and TUG performance was confirmed previously [63]. Mizner et al. [63] found that functional performance assessed by TUG, a stair climbing test, a $6 \mathrm{~min}$ walk test and a sit-to-stand was significantly related to quadriceps strength of both legs. Similar to previous studies $[49,50]$, we showed a significant improvement of TUG performance in the intervention group compared to controls. Thus, contradictory findings might be explained by two major factors: (a) when compared to the study by Moukarzel et al. [21], in all the aforementioned studies, including the present one, the control groups used routine physical therapy (not high-intensity rehabilitation and/or NmES treatment) only, and this might lead to greater loss in performance [49, 50]; (b) different MI approaches used, with ours focusing strictly on strength domain, rather than other symptoms of TKA patients. That is also possibly why there were no significant differences in pain and range of motion measured in the current study.

Self-reported physical function assessed by questionnaires has been increasingly used to assess knee function following TKA surgery $[38,64]$. In the current study, we used the OKS questionnaire, which is a suitable instrument to assess knee function both before and after TKA [38]. However, the OKS score is pain-dependent, suggesting that patients' reporting of functional status is influenced more by their level of perceived pain rather than their ability to perform the task [65]. In the present study, the MIp showed significant improvement in OKS score when compared to controls, while there were no significant changes in pain level after surgery. Therefore, MI practice positively influences self-reported knee function, independent of the patients' pain level.

Some limitations of the present investigation should be highlighted. First, patients were not provided with the fast track model of TKA perioperative practice, which is cost- and time-effective, showing benefits on patients' function and satisfaction as well [66]. Second, our rigorous inclusion criteria narrowed the general conclusions of MI intervention efficiency in TKA patients (e.g., those with a BMI of $40 \mathrm{~kg} / \mathrm{m}^{2}$ or higher and/or receiving bilateral TKA). Third, patients of three different surgeons were included in the current study. However, all three had over 10 years of experience and used the same surgical technique. Fourth, a $24 \%$ loss to follow up might be considered as a limitation of the current study; however, it reflects a real-life scenario which is presumed to happen in clinical studies assessing older patients after major surgery [67]. Also, to alleviate results of interpretation bias from patients lost to follow up, we conducted three-fold analysis, showing no discrepancies between observed results. Future studies should investigate the influence of MI practice on TKA patients with different comorbidities as well as those in other countries, as health care delivery systems and TKA perioperative protocols vary.

\section{Conclusion}

In summary, to our knowledge, this is the first study analysing the effects of MI practice on voluntary activation of the quadriceps muscle and self-reported measure of physical function in patients who underwent TKA surgery. The addition of MI practice to routine physical therapy initiated within $48 \mathrm{~h}$ after TKA preserved the pre-operative level of voluntary activation of the quadriceps muscle and attenuated both objective and subjective measures of physical function at 1 month after TKA. However, the performance of the non-operated leg was not altered, suggesting that MI practice did not exert any statistically significant effect on the contralateral limb for the variables considered in this investigation. MI practice might be a suitable adjunct therapeutic tool to common rehabilitation practice for TKA patients in the early postoperative period.

\section{Abbreviations}

Ml: Motor imagery; VA: Voluntary activation; TKA: Total knee arthroplasty; MIp: Motor imagery practice; CON: Control group; PRE: Evaluation before surgery; POST: Evaluation after surgery; TUG: Timed up-and-go test; MViC: Maximal voluntary isometric strength; OKS: Oxford knee score; OA: Osteoarthritis; RPT: Routine physical therapy

\section{Acknowledgements \\ The authors would like to thank the participants in the study. The authors thank Natalia Zigmund for the daily and initial screening of the patients and all other involved orthopaedic specialists and staff of Valdoltra Orthopaedic Hospital. \\ Authors' contributions \\ A.H.P. and R.P. conceived of the presented idea. A.H.P. performed the calibration of the different devices used in the tests. A.H.P., R.P., and S.K. verified the methods section. All authors discussed the results and contributed to the final manuscript. A.H.P. carried out the tests, A.H.P. wrote the manuscript with support from R.P. and helped supervise the project. N.M. contributed to interpret the data and to finalise the manuscript. A.H.P. contributed to the interpretation of the results and data analysis, and he drafted the manuscript and designed the figures and tables. All authors provided critical feedback and helped shape the research, analysis and manuscript. All authors read and approved the final manuscript.}

Availability of data and materials

The data set of the current study is available as supplementary material. 


\section{Consent for publication}

All participants including patients and control group have permitted to share and publish their information with their own willingness via a declaration form signed by themselves.

\section{Competing interests}

The authors declare that they have no conflict of interest relevant to the content of this article.

Funding

The present study was a part of a PhD project, thus it was partly supported by the Slovenian Research Agency (ARRS).

\section{Author details}

${ }^{1}$ Science and Research Centre Koper, Institute for Kinesiology Research, Koper, Slovenia. ${ }^{2}$ Department of Musculoskeletal Disorders, Faculty of Medicine and Surgery, University of Salerno, Salerno, Italy. ${ }^{3}$ Centre for Sports and Exercise Medicine, Queen Mary University of London, London, UK. ${ }^{4}$ School of Pharmacy and Bioengineering, Keele University School of Medicine, Stoke on Trent, UK. ${ }^{5}$ Orthopaedic Hospital Valdoltra, Ankaran, Slovenia. ${ }^{6}$ Faculty of Sport, University of Ljubljana, Ljubljana, Slovenia.

Received: 27 February 2020 Accepted: 14 September 2020

Published online: 02 October 2020

\section{References}

1. Brooks PM. The burden of musculoskeletal disease - a global perspective. Clin Rheumatol. 2006;25(6):778-81.

2. Salaffi DA. R, Grassi W. Prevalence of musculoskeletal conditions in an Italian population sample: results of a regional community-based study. I. The MAPPING study. Scand J Rheumatol. 2007;36(1):14-21.

3. Bourne R. Remains of the day: Outcome measurements in total knee arthroplasty. Orthopedics. 2000;23:995-8.

4. Khanna A, Gougoulias N, Longo UG, Maffulli N. Minimally invasive total knee arthroplasty: a systematic review. Orthop Clin North Am. 2009;40(4):479-89.

5. Schache MB, McClelland JA, Webster KE. Lower limb strength following total knee arthroplasty: A systematic review. Knee. 2014:21(1):12-20.

6. Mizner PSC, Stevens JE, Axe MJ, Snyder-Mackler L. Preoperative quadriceps strength predicts functional ability one year after total knee arthroplasty. J Rheumatol. 2005;32(8):1533-9.

7. Mizner P. S, Stevens E, Vandenborne K, Snyder-Mackler L. Early quadriceps strength loss after total knee arthroplasty. J Bone Jt Surg. 2005;87-A(5):104754.

8. Holm B, Kristensen MT, Bencke J, Husted H, Kehlet H, Bandholm T. Loss of knee-extension strength is related to knee swelling after total knee arthroplasty. Arch Phys Med Rehabil. 2010;91(11):1770-6.

9. Morita S, Kusaka T, Tanaka S, Yamada E, Arima N, Itoh S, et al. The relationship between muscle weakness and activation of the cerebral cortex early after unicompartmental knee arthroplasty. J Phys Ther Sci. 2013;25(3): 301-7.

10. Paravlic AH, Kovač S, Pisot R, Marusic U. Neurostructural correlates of strength decrease following total knee arthroplasty: A systematic review of the literature with meta-analysis. Bosn J basic Med Sci. 2019;20(1):1-12.

11. Jeannerod. The representing brain: neural correlates of motor intention and imagery. Behav Brain Sci 1994;17(2):187-245.

12. Slimani M, Tod D, Chaabene H, Miarka B, Chamari K. Effects of mental imagery on muscular strength in healthy and patient parti...: Search USA (multiple databases and sources). J Sport Sci Med. 2016;15(3):434-50.

13. Paravlic AH, Slimani M, Tod D, Marusic U, Milanovic Z, Pisot R. Effects and dose-response relationships of motor imagery practice on strength development in healthy adult populations: a systematic review and metaanalysis. Sport Med. 2018;48(5):1165-87.

14. Kanthack TFD, Guillot A, Papaxanthis C, Guizard T, Collet C, Di Rienzo F. Neurophysiological insights on flexibility improvements through motor imagery. Behav Brain Res. 2017;331(September):159-68.

15. Forward JB, Greuter NE, Crisall JS, Lester HH. Effect of structured touch and guided imagery for pain and anxiety in elective joint replacement patients_a randomized controlled trial: M-TIJRP. Perm J. 2015;19(4):18-28.

16. Hoyek N, Di Rienzo F, Collet C, Hoyek F, Guillot A. The therapeutic role of motor imagery on the functional rehabilitation of a stage II shoulder impingement syndrome. Disabil Rehabil. 2014;36(13):1113-9.
17. Tamir R, Dickstein R, Huberman M. Integration of motor imagery and physical practice in group treatment applied to subjects with Parkinson's disease. Neurorehabil Neural Repair. 2007;21(1):68-75.

18. Li ZM, Tan JY, Chen GL, Lin WY. Effects of motor imagery on walking function and balance in patients after stroke: A quantitative synthesis of randomized controlled trials. Complement Ther Clin Pract. 2017;28(1):75-84.

19. Zach S, Dobersek U, Filho E, Inglis V, Tenenbaum G. A meta-analysis of mental imagery effects on post-injury functional mobility, perceived pain, and self-efficacy. Psychol Sport Exerc. 2018;34:79-87.

20. Marusic U, Grosprêtre S, Paravlic A, Kovač S, Pišot R, Taube W. Motor imagery during action observation of locomotor tasks improves rehabilitation outcome in older adults after total hip arthroplasty. Neural Plast. 2018;2018(March):1-9.

21. Moukarzel M, Di Rienzo F, Lahoud J-C, Hoyek F, Collet C, Guillot A, et al. The therapeutic role of motor imagery during the acute phase after total knee arthroplasty: a pilot study. Disabil Rehabil. 2017;41(8):926-33.

22. Jacobson AF, Umberger WA, Palmieri PA, Alexander TS, Myerscough RP, Draucker CB, et al. Guided imagery for total knee replacement: a randomized, placebo-controlled pilot study. J Altern Complement Med. 2016;22(7):563-75

23. Grezes J, Decety J. Functional anatomy of execution, mental simulation, observation, and verb generation of actions: a meta-analysis. Hum Brain Mapp. 2001;12(September 2000):1-19.

24. Knight CA, Kamen G. Relationships between voluntary activation and motor unit $W$ ring rate during maximal voluntary contractions in young and older adults. Eur J Appl Physiol. 2008;103(6):625-30.

25. Hopkins WG. Estimating sample size for magnitude-based inferences. Sportscience. 2006;10:63-70.

26. Norman GR. Point/counterpoint interpretation of changes in health-related quality of life the remarkable universality of half a standard deviation. Med Care. 2003;41(5):582-92.

27. Sakpal T. Sample size estimation in clinical trial. Perspect Clin Res. 2010;1(2):67-9.

28. Hoffmann TC, Glasziou PP, Boutron I, Milne R, Perera R, Moher D, et al. Better reporting of interventions: Template for intervention description and replication (TIDieR) checklist and guide. BMJ. 2014;348(March):1-12.Available from. https://doi.org/10.1136/bmj.g1687.

29. Lindheimer JB, O'Connor PJ, Dishman RK. Quantifying the placebo effect in psychological outcomes of exercise training: a meta-analysis of randomized trials. Sport Med. 2015;45(5):693-711.

30. Merton P. Voluntary strength and fatigue. J Physiol. 1954;123:553-64.

31. Strojnik V, Komi PV. Neuromuscular fatigue after maximal stretch-shortening cycle exercise. J Appl Physiol. 1998;84(1):344-50.

32. Jaric $S$. Role of body size in the relation between muscle strength and movement performance. Exerc Sport Sci Rev. 2003;31(1):8-12.

33. Podsiadlo D, Richardson S. The timed "Up \& Go": a test of basic functional mobility for frail elderly persons. J Am Geriatr Soc. 1991;39(2):142-8.

34. Steffen TM, Hacker T a, Mollinger L. Age- and gender-related test performance in community-dwelling elderly people: six-minute walk test, Berg Balance Scale, Timed Up \& Go Test, and Gait Speeds. Phys Ther. 2002; 82(2):128-37.

35. Mizner PS, Snyder-Mackler L. Quadriceps Strength and the time course of functional recovery after total knee arthroplasty. J Orthop Sport Phys Ther. 2005:35:424-36.

36. Cibere J, Thorne A, Bellamy N, Greidanus N, Chalmers A, Mahomed N, et al. Reliability of the knee examination in osteoarthritis: effect of standardization. Arthritis Rheum. 2004;50(2):458-68.

37. Hawker GA, Mian S, Kendzerska T, French M. Measures of adult pain: visual analog scale for pain (VAS Pain), Numeric Rating Scale for Pain (NRS Pain), McGill Pain Questionnaire (MPQ), Short-Form McGill Pain Questionnaire (SFMPQ), Chronic Pain Grade Scale (CPGS), Short Form-36 Bodily Pain Scale (SF). Arthritis Care Res. 2011;63(SUPPL. 11):240-52.

38. Jenny JY, Diesinger Y. The Oxford Knee Score: Compared performance before and after knee replacement. Orthop Traumatol Surg Res. 2012; 98(4):409-12.

39. Hopkins MSW, Batterham AM, Hanin J. Progressive Statistics for Studies in Sports Medicine and Exercise Science. Med Sci Sport Exerc. 2009:41(1):3-13.

40. Hsiao Y-H, Chien S-H, Tu H-P, Fu JC-M, Tsai S-T, Chen Y-S, et al. Early PostOperative Intervention of Whole-Body Vibration in Patients After Total Knee Arthroplasty: A Pilot Study. J Clin Med. 2019:8(11):1902.

41. Hurley MV. The effects of joint damage on muscle function, proprioception and rehabilitation. Man Ther. 1997;2(1):11-7. 
42. Maffulli N, Spiezia F, La Verde L, Rosa MA, Franceschi F. The management of extensor mechanism disruption after total knee arthroplasty. Sports Med Arthrosc. 2017;25(1):41-50.

43. Gerbershagen HJ, Aduckathil S, van Wijck AJM, Peelen LM, Kalkman CJ, Meissner W. Pain intensity on the first day after surgery. Anesthesiology. 2013;118(4):934-44.

44. Wang C, Zhou C, Qu H, Yan S, Pan Z. Comparison of tourniquet application only during cementation and long-duration tourniquet application in total knee arthroplasty : a meta-analysis. J Orthop Surg Res. 2018;13(216):1-10.

45. Geborek P, Månsson B, Wollheim FA, Moritz U. Intraarticular corticosteroid injection into rheumatoid arthritis knees improves extensor muscles strength. Rheumatol Int. 1990;9(6):265-70

46. Hopkins JT, Ingersoll CD. Arthrogenic muscle inhibition: a limiting factor in joint rehabilitation. J Sport Rehabil. 2000;9(2):135-59.

47. Mizner SJE, Snyder-Mackler L. Voluntary activation and decreased force production of the quadriceps femoris muscle after total knee arthroplasty. Phys Ther. 2003;83(4):359-65.

48. Stevens JE, Mizner RL, Snyder-Mackler L. Quadriceps strength and volitional activation before and after total knee arthroplasty for osteoarthritis. J Orthop Res. 2003;21(5):775-9.

49. Bade S-LJE. Early high-intensity rehabilitation following total knee arthroplasty improves outcomes. J Orthop Sport Phys Ther. 2011;41(12): 932-41.

50. Stevens-Lapsley JE, Balter JE, Wolfe P, Eckhoff DG, Kohrt WM. Early neuromuscular electrical stimulation to improve quadriceps muscle strength after total knee arthroplasty: a randomized controlled trial. Phys Ther. 2012; 92(2):210-26.

51. Park JS, Choi J-B, Kim W-J, Jung N-H, Chang M. Effects of combining mental practice with electromyogram-triggered electrical stimulation for stroke patients with unilateral neglect. J Phys Ther Sci. 2015;27(11):3499-501 Available from: https://www.jstage.jst.go.jp/article/jpts/27/11/27_.jpts-2 015-560/_article.

52. Hong IK, Choi JB, Lee JH. Cortical changes after mental imagery training combined with electromyography-triggered electrical stimulation in patients with chronic stroke. Stroke. 2012;43(9):2506-9.

53. Bonassi G, Biggio M, Bisio A, Ruggeri P, Bove M, Avanzino L. Provision of somatosensory inputs during motor imagery enhances learning-induced plasticity in human motor cortex. Sci Rep. 2017;7(1):1-10.Available from: http://dx.doi.org/https://doi.org/10.1038/s41598-017-09597-0.

54. Cupal DD, Brewer BW. Effects of relaxation and guided imagery on knee strength, reinjury anxiety, and pain following anterior cruciate ligament reconstruction. Rehabil Psychol. 2001;46(1):28-43.

55. Hanakawa T, Dimyan MA, Hallett M. Motor planning, imagery, and execution in the distributed motor network: A time-course study with functional MRI. Cereb Cortex. 2008;18(12):2775-88

56. Ruffino C, Papaxanthis C, Lebon F. Neural plasticity during motor learning with motor imagery practice: Review and perspectives. Neuroscience. 2017; 341:61-78.

57. Tong Y, Pendy JT, Li WA, Du H, Zhang T, Geng X, et al. Motor ImageryBased Rehabilitation: Potential Neural Correlates and Clinical Application for Functional Recovery of Motor Deficits after Stroke. Aging Dis. 2017;8(3):364.

58. Kosslyn SM, Ganis G, Thompson WL, Hall WJ. Neural foundations of imagery. Nature. 2001;2(September):635-42.

59. Munzert J, Lorey B, Zentgraf K. Cognitive motor processes: the role of motor imagery in the study of motor representations. Brain Res Rev. 2009;60(2): 306-26.

60. Ranganathan S. V, Liu JZ, Sahgal V, Yue GH. From mental power to muscle power - Gaining strength by using the mind. Neuropsychologia. 2004;42(7): 944-56.

61. Yao WX, Ranganathan VK, Allexandre D, Siemionow V, Yue GH. Kinesthetic imagery training of forceful muscle contractions increases brain signal and muscle strength. Front Hum Neurosci. 2013;7(9):561.

62. Lebon F, Guillot A, Collet C. Increased muscle activation following motor imagery during the rehabilitation of the anterior cruciate ligament. Appl Psychophysiol Biofeedback. 2012;37(1):45-51.

63. Mizner S-ML. Altered loading during walking and sit-to-stand is affected by quadriceps weakness after total knee arthroplasty. J Orthop Res. 2005;23(5): 1083-90.

64. Murray DW, Fitzpatrick R, Rogers K, Pandit H, Beard DJ, Carr AJ, et al. The use of the Oxford hip and knee scores. J Bone Jt Surg - Br Vol. 2007;89-B(8): 1010-4.
65. Hamilton DF, Gaston P, Simpson AHRW. Is patient reporting of physical function accurate following total knee replacement? Bone Joint J. 2012;94$B(11): 1506-10$.

66. Husted H. Fast-track hip and knee arthroplasty: Clinical and organizational aspects. Acta Orthop. 2012;83(SUPPL.346):1-39.

67. Gómez-Barrena E, García-Rey E. Complications in total joint arthroplasties. J Clin Med. 2019;8(11):1891.

\section{Publisher's Note}

Springer Nature remains neutral with regard to jurisdictional claims in published maps and institutional affiliations.
Ready to submit your research? Choose BMC and benefit from:

- fast, convenient online submission

- thorough peer review by experienced researchers in your field

- rapid publication on acceptance

- support for research data, including large and complex data types

- gold Open Access which fosters wider collaboration and increased citations

- maximum visibility for your research: over $100 \mathrm{M}$ website views per year

At BMC, research is always in progress.

Learn more biomedcentral.com/submissions 